\title{
RETROSPECTIVA: 20 AÑOS DE LA REVISTA \\ ESTUDIOS DE LINGÜÍSTICA. UNIVERSIDAD DE ALICANTE
}

\author{
Tomás Albaladejo \\ Universidad Autónoma de Madrid \\ tomas.albaladejo@uam.es
}

Hace veinte años que en la Universidad de Alicante, en el que entonces se Ilamaba Departamento de Lengua Española, decidimos poner en marcha una revista que recogiera publicaciones relacionadas con las materias que correspondían al Departamento, que eran todas las de Lengua Española, Lingüística General y Crítica Literaria, en la medida en que las líneas de investigación de sus miembros estaban situadas en los campos de dichas materias. Pero no queríamos que la revista fuera una publicación del profesorado del Departamento, que contuviera exclusivamente, ni siquiera principalmente, sus trabajos. Fue un acierto no optar por esa vía fácil pero con toda seguridad empobrecedora para la revista, que la habría llevado a una desaparición anunciada, aun cuando sus números hubieran seguido publicándose. Desde el primer momento pensamos que la revista debía contener, junto a publicaciones de los miembros del Departamento, a las que justamente contribuiría a dar difusión, publicaciones de investigadores e investigadoras de otras universidades y centros de España y de fuera de España. Habíamos decidido hacer una revista abierta y plural, en la que las distintas perspectivas metodológicas y los diferentes planteamientos de estudio teórico-crítico del lenguaje y de la literatura tuvieran cabida, una revista en la que trabajos resultantes de nuestra investigación aparecieran junto a trabajos procedentes de la investigación que se hacía en otras universidades y centros.

El nombre que dimos a la revista, Estudios de Lingüistica. Universidad de Alicante, respondía a la voluntad de representar del modo más adecuado posible la realidad de las materias del Departamento cuando todavía no existían las áreas de conocimiento, que se instauraron con uno de los decretos de desarrollo de la Ley de Reforma Universitaria de 1983. También -todo hay que decirlo- tuvimos en cuenta que ELUA sonaba bien. En el propio Departamento nos encargamos de hacer el diseño de la revista, incluida la portada. En el número 1 (1983) de la revista no pusimos ningún subtítulo. Fue a partir del número 2 (1984) cuando añadimos Revista de Lengua Española, Lingüistica General y Crítica Literaria, subtítulo que se mantuvo hasta el número 5 (1988-1989). A partir de 1986 ya no existía el Departamento de Lengua Española, sino el nuevo Departamento de Filología Española, Lingüística General y Teoría de la Literatura, que es su actual denominación.

Los primetos cinco números de ELUA forman la que se puede considerar primera etapa de la revista, en la que sus contenidos corresponden principalmente a las materias del inicial Departamento de Lengua Española (las que serían áreas de Filología Española -en su parte 
de Lengua Española-, Lingüística General y Teoría de la Literatura). En esta primera etapa de la revista, los números contienen trabajos de lingüística del español y de otras lenguas, con atención a los distintos niveles del objeto lingüístico, de sociolingüística, de lingüística del texto, de gramática generativa, de historia de la lingüística, de historia de la lengua española, de retórica y de teoría y crítica literarias desde diferentes perspectivas y planteamientos metodológicos, con predominio de los centrados en los aspectos lingüísticos de la literatura. La presencia de estos artículos sobre literatura, que no dejan de participar de la común fundamentación lingüística de ELUA, es uno de los rasgos distintivos de la primera etapa de la revista en relación con la segunda y responde a la vinculación del área de Teoría de la Literatura a la revista, sin que deba olvidarse que en la Universidad de Alicante, como en otras Universidades, dicha área se constituyó a partir de la antigua Gramática General y Crítica Literaria, con la consiguiente conexión de ambas partes de esta denominación de plazas.

A partir del número 6 (1990), ELUA lleva el subtítulo de Revista de Lengua Española y Lingüistica General, respondiendo a una nueva configuración de la revista, que dejaba abiertos caminos propios al área de Teoría de la Literatura, en la que no se tardaría en proponer una revista de números monográficos: Teoria/Crítica. Con el número 6 comienza la segunda etapa de $E L U A$, centrada ya en la publicación de trabajos de lingüística del español y de otras lenguas y de lingüística general. No obstante, en esta segunda etapa también hay trabajos en los que se atiende a la problemática de la lengua literaria y a aspectos lingüísticos de la obra literaria. ELUA ofrece, tanto en su segunda como en su primera etapa, una especial atención a la dimensión textual y discursiva del lenguaje, con sus implicaciones semióticas, sin desatender dentro de éstas ni las pragmáticas, ni las semánticas, ni las sintácticas. La atención a la lingüística cognitiva, a cuestiones de traducción, a la adquisición de lenguas, así como a otras muchas cuestiones de la mayor actualidad en los estudios lingüísticos, caracteriza esta segunda etapa, con el mantenimiento de los planteamientos innovadores presentes desde el nacimiento de la revista.

Lejos están los tiempos en los viajábamos desde Alicante a Alcoy para llevar los originales de la revista y para hacer las últimas correcciones de las pruebas de imprenta, por el Port de la Carrasqueta, si las condiciones meteorológicas lo permitían, o a Patiño, en Murcia, para la composición de la revista. Sin embargo, no están lejanas la ilusión y la voluntad iniciales de hacer una revista de interés en el ámbito de los estudios lingüísticos ampliamente entendidos, ya que esta ilusión y esta voluntad persisten veinte años después en el trabajo del equipo que hace $E L U A$ en la actualidad.

Madrid, diciembre de 2003 